\title{
Research efficiency of complex systems with spread spectrum renewable energy for electric power supply decentralized objects in Russia
}

\author{
V. I. Velkin \\ Ural Federal University named after the first President of Russia \\ Boris Yeltsin, Russia
}

\begin{abstract}
The urgency of using the integrated systems of renewable energy sources (RES clusters) within the significant area of the Russian Federation is demonstrated. The theoretical background of the methodology of cluster approach and substantiation of calculation of the optimal composition of the equipment of renewable energy sources within a RES cluster are presented. The analogy between the RES clusters and the Markowitz-Sharpe-Tobin portfolio theory is shown. The graphical model for searching for the optimal RES cluster and the algorithm of computation program are presented. The results of using various RES clusters for an experimental object "An Energy Efficient House" are considered. The resulting computed data and the experimental data demonstrate that the energy performance of optimized integrated systems (RES clusters) can be increased by up to $20-40 \%$ in terms of energy generation. The comparative performance of the existing RES cluster imported from China and the one optimized using the proposed methodology and the elaborated algorithm is shown.

Keywords: renewable energy sources (RES), optimization of RES equipment, RES cluster, J. Tobin's theory of optimal portfolio selection.
\end{abstract}

\section{Introduction}

Renewable energy sources (RES) are more and more commonly used around the world; however, the rate of their implementation in Russia is much slower [1]. This situation can be explained by the significant hydrocarbon reserves and relatively low relative indicators of natural environmental and climatic factors 
(wind speed [2] and insolation [3]) across the largest part of the territory of the country.

In this context, the diversification of power supply to the consumers by simultaneous using of different energy sources is of significance within this area. This can be achieved via using RES clusters [4].

The accurate and economically reasonable ratios between the capacities of different RES clusters in different regions require complex mathematical computations to be carried out. A discrete stochastic model of a RES cluster, which makes allowance a number of significant factors, has been proposed in order to solve this problem [5].

\section{Theoretical foundations of the mathematical model of the RES cluster}

The mathematical model of the RES cluster is based on the analogy with the Markowitz [6] and Sharpe's [7] portfolio theory with the only difference that the RES cluster uses insolation and wind speed as stochastic parameters, while the U.S. Nobel laureates H.M. Markowitz and W.F. Sharpe uses various risk stocks in the stock market. In his model of the optimal portfolio, Markowitz's pupil and follower, Nobel Prize winner J. Tobin considered the combination of risk-free stocks (government securities) and risk stocks in the stock market [8]. The geometrical interpretation of the J. Tobin's model of optimal portfolio is shown in Fig. 1.

In this diagram, risk-free assets (the $\mathrm{Y}$ axis) mean low-yield but reliable and almost risk-free government securities and liabilities.

The optimal portfolio is characterized by the highest yield and the minimal risk can be found at point $\mathrm{M}$, which lies on the tangent line drawn from the cost of government securities (risk-free assets) to the hyperbola representing a lot of stock in the stock market.

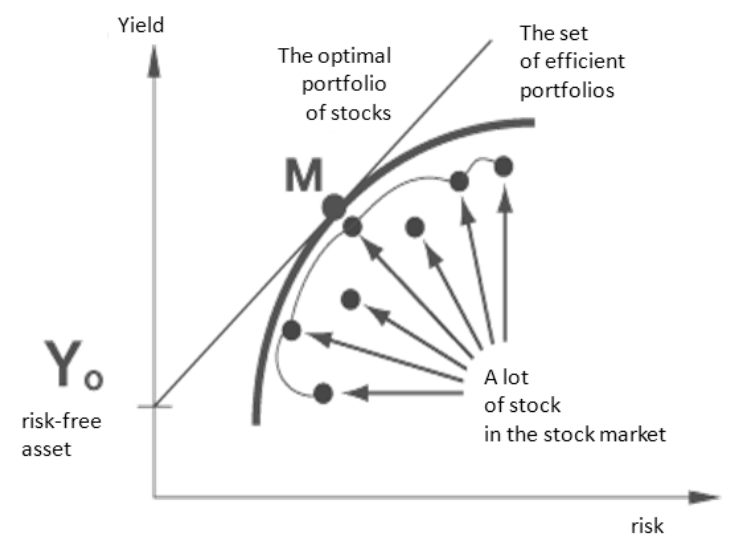

Figure 1: Diagram showing the yield, risks, and the optimal portfolio of stocks according to J. Tobin's theory. 


\section{Analogy with the RES cluster}

A diesel generator is assumed to be a risk-free energy source in the RES cluster. Wind and insolation are risky energy sources because of their stochasticity.

The use of the discrete mathematic model and the analysis of the statistic data on stochastic parameters allows one to determine the RES configuration that would be optimal for a specific region (in terms of its composition and equipment capacity) using the "Search for a solution" module in the standard MS EXCEL software package.

The quadratic function of $x_{1}, x_{2}, \ldots, x_{n}$ :

$$
D(Y / a)=\sum_{i=1}^{n} \sum_{j=1}^{n} \sigma_{i j} x_{i} x_{j},
$$

was used as the target function for the mathematic model of the RES cluster, where $\mathrm{x}_{\mathrm{i}}$ is the share of the determined capacity for each type of renewable energy sources in the RES cluster; $\sigma_{i j}$ is the sample covariance calculated using samples for $\boldsymbol{Y}_{\boldsymbol{i}}$ and $\boldsymbol{Y}_{\boldsymbol{j}}$.

The physical meaning of this function is dispersion of the cost of energy generated by a RES cluster per time unit.

\section{Comparison of the calculated and experimental data}

The calculated parameters obtained using a mathematical model and the corresponding calculations were compared to the experimental data accumulated during the period of usage of the "Energy Efficient House". The house is an actual residential townhouse consisting of 8 apartments (cottages). Its own RES cluster was mounted in each apartment. The configuration of the RES clusters in the apartments is as follows:

$1-$ an octa-RES cluster $(\mathrm{DG}+\mathrm{WT}+\mathrm{PV}-\mathrm{P}+\mathrm{sHEP}+\mathrm{SC}+\mathrm{HP}+\mathrm{BGU}+$ Batt);

$2-$ a penta-RES cluster (DG+ WT $+\mathrm{PV}-\mathrm{P}+\mathrm{SC}+\mathrm{Batt})$;

3, 4, 5 - a duplex RES cluster (DG+WT);

$6-$ a trio-RES cluster (DG + PV-P + Batt);

7 - a sept-RES cluster (DG + PV-P + WT + SC + BH + mHEP + Batt $)$;

$8-$ a quatro-RES cluster $(\mathrm{DG}+\mathrm{WT}+\mathrm{SC}+\mathrm{Batt})$.

The high level of similarity of each object (ceiling height, area and volume of the rooms, heat-shielding characteristics, arrangement of the heating appliances, windows, etc.) containing different RES clusters ensured good comparability of the resulting experimental data and the reliability of their comparison to the calculated parameters.

The minimum cost of production of one kilowatt-hour at a given simple payback period was used as the criterion of efficiency of a RES cluster.

Fig. 2 shows the composition of equipment of the RES clusters for the apartments in the "Energy Efficient House". 


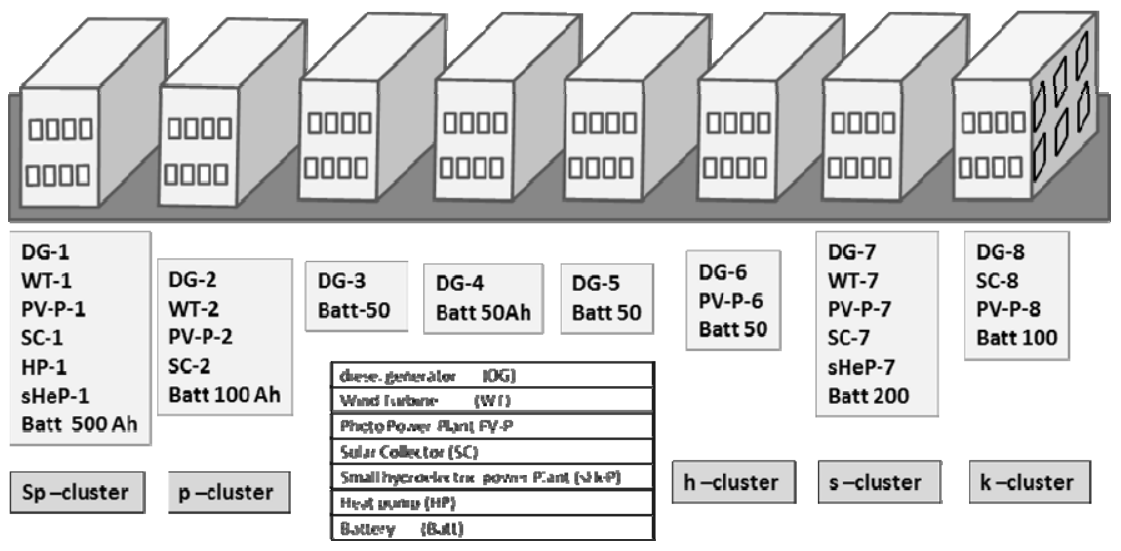

Figure 2: Composition of the equipment of the RES clusters in the apartments of the "Energy Efficient House".

The proposed algorithm (Fig. 3) for calculating the optimal share of each renewable energy source in the RES cluster was used to design, test, and register the automated software program for rapid determination of the optimal parameters of the RES cluster (ARC-RES - the automated calculation of the RES cluster) [9].
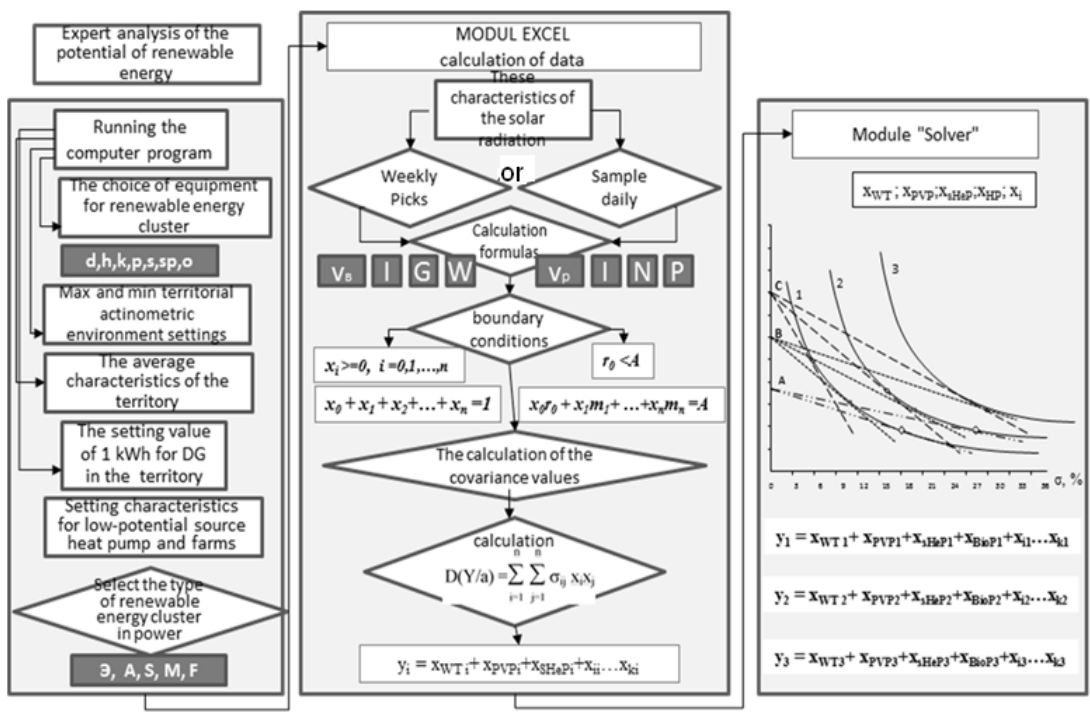

Figure 3: Algorithm for computation of the optimal RES cluster based on the stochastic data of long-term observations of actinometric characteristics. 
The experimental data and calculated characteristics of the optimal RES cluster are shown in Fig. 4.

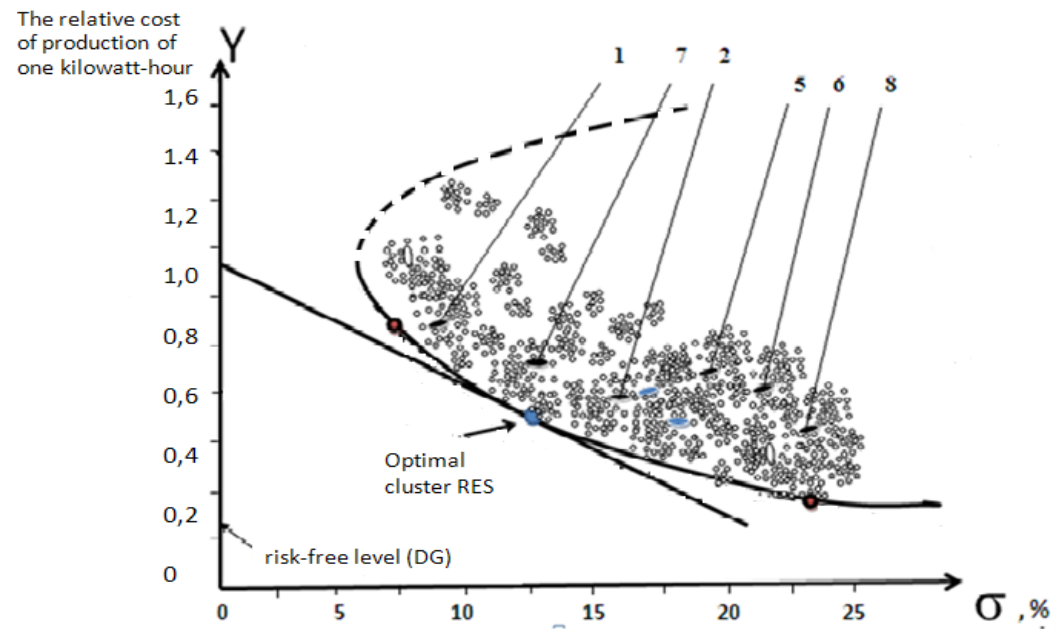

Figure 4: The experimental data for apartments (1-8) corresponding to clusters of RES and the design characteristics of the optimal cluster RES.

Almost all the RES clusters in the "Energy Efficient House" formed without the scientifically justified configuration did not comply with the optimal ratio between the shares of capacity between the types of RES equipment; hence, their efficiency can be increased. This reserve is determined by the relative value of $20-40 \%$ per each produced $1 \mathrm{kWh}$, which corresponds to underproduction (or loss) of $20-40 \%$ of the potential energy of the functioning RES equipment.

\section{Visualization of the efficiency of the RES cluster}

The efficiency of using the ARC-RES program can be visualized on a diagram of the model of the calculated RES cluster and the one provided as a part of the equipment imported from China (Fig. 4).

Table 1 displays the composition of the equipment in the RES cluster imported from China, while Table 2 shows the composition of the RES cluster optimized using the same nomenclature. It follows from the diagram in Fig. 5 that the prime cost of energy production by the China RES cluster is higher by $20-40 \%$ (points 1 and 2 in the zoomed-in fragment of the diagram); however, the risk (probability that no energy is produced due to the potentially low wind speed and low insolation level) is $10-15 \%$ lower for the optimized cluster. The latter circumstance is random for this cluster, since the multifactor mathematical model can be optimized only for a single criterion (in this case, for prime cost of energy production). 

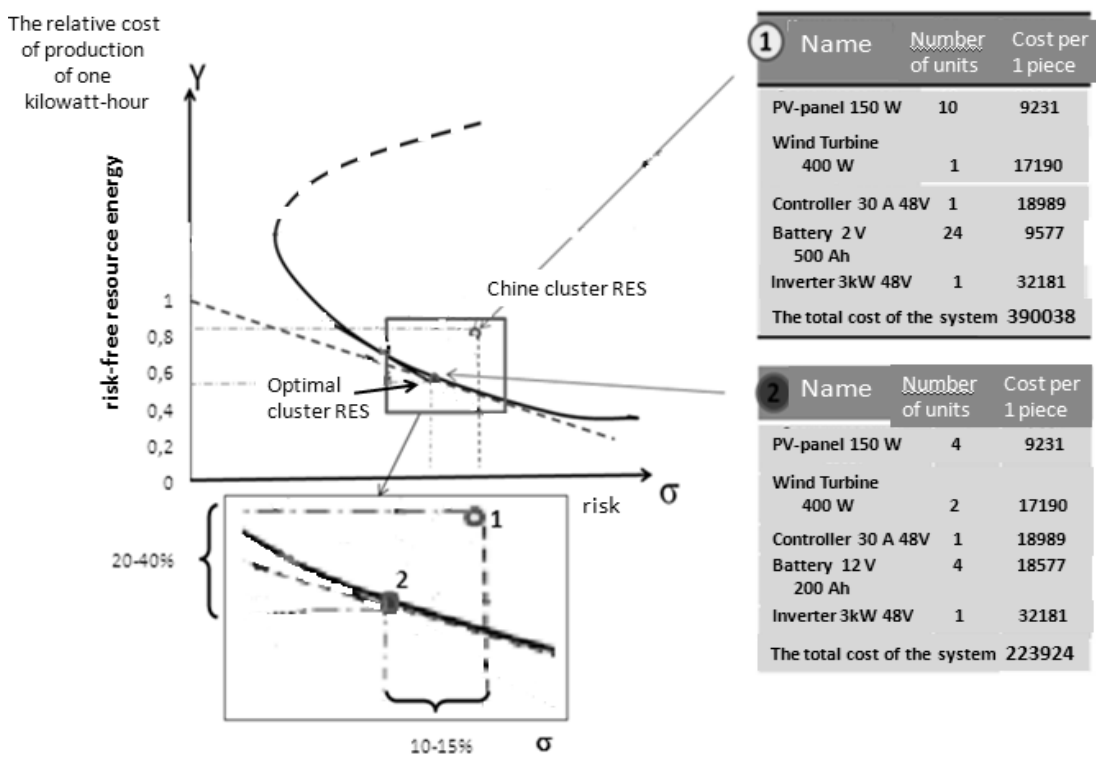

Figure 5: Graphical comparison of the regular model kit d-cluster RES China (1) and the renewable energy cluster (2) of the same manufacturer optimized by the program "ARC-RES".

The results of comparing power production by the China RES cluster and the optimized cluster are listed in Table 1.

Table 1: $\quad$ Parameters of energy generation and cost of RES clusters.

\begin{tabular}{|c|c|c|}
\hline $\begin{array}{c}\text { Parameter (calculated for the conditions of the } \\
\text { Ural Region) }\end{array}$ & China & ARC-RES \\
\hline $\begin{array}{c}\text { Electrical power production during winter time } \\
\text { (December), kWh/month }\end{array}$ & $\mathbf{4 0}$ & $\mathbf{9 2}$ \\
\hline $\begin{array}{c}\text { Electrical power production during summer time } \\
\text { (April-September), kWh/month }\end{array}$ & $\mathbf{1 5 9 . 9}$ & $\mathbf{1 0 1 . 0}$ \\
\hline $\begin{array}{c}\text { Total cost of the RES d-cluster (thousand rubles) } \\
\text { (WT+PV-P) }\end{array}$ & $\mathbf{3 9 0}$ & $\mathbf{2 2 4}$ \\
\hline
\end{tabular}

Thus, the equipment kit imported from China (without optimization of the capacity of WT and PV-P) is twice as expensive, while the production of electrical power during the crucial winter months in the Ural Region is lower more than twofold as compared to these parameters of the RES cluster optimized using the proposed ARC-RES algorithm. The total electrical power production by a China RES cluster per year is comparable to that of the optimized RES cluster; however, it is attained due to the increased energy production during the summer time. The excess energy produced by the China RES cluster cannot be 
accumulated, since the batteries rapidly discharge to $0 \%$ during summer time, while the discharge of the excess energy to the power supply network is prohibited by Russian legislation.

The graphical analysis of construction of the optimal RES clusters for different areas was shown in Fig. 6.

The optimal RES cluster lies at the point of the tangent line drawn from the level of relative cost of production of 1 kiloWatt-hour by a risk-free energy source (diesel generator, DG) (points A; B; C) to the proper hyperbola (1-5). Each of three scales of the $\mathrm{Y}$ axis corresponds to the proper cost of production of $1 \mathrm{kWatt}-\mathrm{hour}$ and can be assessed using absolute units for a specific region that a RES cluster is located at.

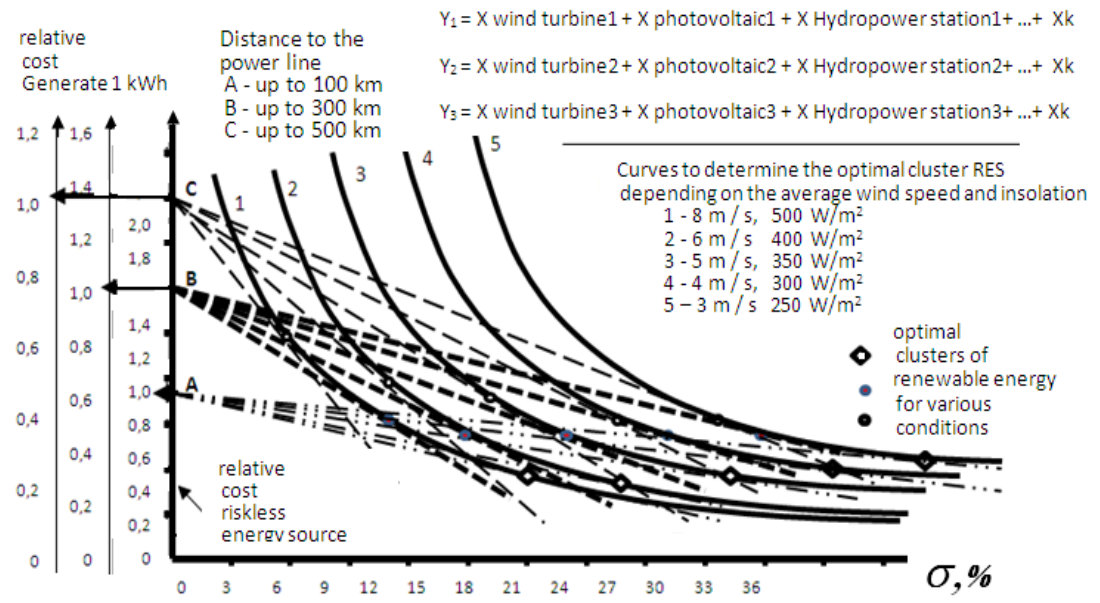

Figure 6: Diagram for comparing the optimal RES clusters depending on the relative cost of generation of $1 \mathrm{kWh}$ as a function of distance to the central energy sources (power lines) and actinometric parameters at the consumer's site.

The resulting calculation data and the experimental results demonstrate that the energy efficiency of the optimized integrated systems (RES clusters) can be improved up to $20-40 \%$ during power production.

\section{Conclusions}

1. The proposed graphical model of the RES cluster allows one to determine the optimal renewable energy sources (in terms of capacity and equipment configuration) for the remote areas of the Russian Federation, where the power efficiency and reliability of power supply need to be improved. 
2. Further development of RES clusters includes manufacturing ready-to-use RES complexes organized as modules, with the variety of power from several $\mathrm{kW}$ to $1 \mathrm{MW}$ to be used in remote decentralized objects and areas.

\section{References}

[1] Bezrukih, P.P. and D.S. Strebkov, 2002. Renewable Energy in the Third Millennium. Outlook from Russia. In Materials of Business and Technical Seminar for Power Engineering. Capetown, pp: 5.

[2] Nikolaev, V.G., S.V. Ganaga and Y.I. Kudryashov, 2010. Prospects of Development of Renewable Power Sources (RES) in the Russian Federation. The Results of TASIS Project. EUROPE Aid/116951/C/SV/RU. Moscow: Atmograph.

[3] Popel', O.S. and Yu.G. Frid, 2010. Atlas of the Resources of Solar Energy in Russian Federation (in Russian).

[4] Vel'kin, V.I., 2012. Optimization of the choice for power supply using the cluster approach when applying renewable energy sources. Alternative Power Engineering and Environment, 2: 67-71 (in Russian).

[5] Vel'kin, V.I., M.I. Loginov and E.V. Chernobai, 2013. Development of the mathematical model and software to compute the RES cluster. Advances in Mathematics, 1: 66-70 (in Russian).

[6] Markowitz, H.M., 1990. Mean-Variance Analysis in Portfolio Choice and Capital Markets. Cambridge, MA: Blackwell.

[7] Sharpe, W.F., 1963. A Simplified Model for Portfolio Analysis. Management Science.

[8] Tobin, J., 1965. The Theory of Portfolio Selection. In The Theory of Interest Rate, Eds., Hahn, F.N. and F.R.P. Brechling. London: Macmillan, pp: 3-51.

[9] Vel'kin, V.I., M.I. Loginov and E.V. Chernobai, 2013. State Registration Certificate of Computer Program № 2,013,613,097; Computer Program for Automated Computation of RES Cluster “ARC-RES”. Registered March 25, 013 (in Russian). 